\title{
DETERMINATION OF SULFUR CONTENT IN WASTE MATERIALS BY ION CHROMATOGRAPHY
}

Ileana Crina Nicolescu, Elena Bucur, Agnes Serbanescu, Raluca Diodiu, Mona Barbu

National Research and Development Institute for Industrial Ecology -ECOIND, 71-73 Drumul

Podu Dambovitei, 060652, Bucharest, Romania, ileana.nicolescu@incdecoind.ro

\begin{abstract}
The aim of this work is to apply an ion - chromatography method which was initially developed for the determination of sulfur content in fuels, on other classes of samples as municipal waste and oil and sewage sludge.

With respect to their physical properties and texture, solid waste materials as municipal waste, are typically strongly heterogeneous and thus, sample preparation can be critical in obtaining reliable analysis results so that, particle size reduction and homogenizing of the municipal waste was an important step in conducting the experiments. The homogenization of the samples was performed by cutting and then grinding the material in two steps: first a reduction of the particles to diameters passing a 10-mm sieve and secondly to diameters passing a 2-mm sieve.

The sulfur extraction from the homogenized waste samples was carried out by the combustion method in the calorimetric bomb. Sulfur as sulfate anion was then analyzed by ion-chromatography and gravimetric techniques and the results were compared. Depending on the nature and sulfur content of the sample, the repeatability standard deviation $\mathrm{Sr}_{\mathrm{r}}$ and the relative repeatability standard deviation RSD of the results were of the same order of magnitude for the both gravimetric and ion chromatography methods and they were in the range of about $0.01-0.05 \%$ for $\mathrm{sr}$ and in the range of about $3.23-6.25 \%$ for RSD.
\end{abstract}

Keywords: ion-chromatography, municipal waste, oil sludge, sewage sludge, sulfur

\section{Introduction}

According to the European legislation, preventing the waste generation and performing an adequate management (recovery/disposal) is a strategy focusing on the prioritization of practical actions taking into account the sustainable development principles (Arama 2016). The term "waste" means any solid, liquid or contained gaseous material that is discharged by being disposed of, burned, incinerated or recycled (Puiu 2016). Conventional fuels (coal / petroleum coke, fuel oil or methane gas) or conventional raw materials (limestone, clay, marl, loess, bentonite) traditionally used in the cement manufacturing process, could be partially replaced by the waste with a composition corresponding to the requirements of the technological process, the quality requirements and the environmental protection.

There are also types of waste that have a relatively low calorific value, but with a mineralogical content similar to those of conventional raw materials, these wastes could be exploited by recovering both their energy and material value. The essential condition at the recovery of the wastes is to not lead to a significant increase of pollutants in air emissions and of harmful substances in the finished product. This is also achieved by quantitative limitations of the pollutants content in waste, which are 


\section{INTERNATIONAL SYMPOSIUM "THE ENVIRONMENT AND THE INDUSTRY", SIMI 2017, PROCEEDINGS BOOK}

intended to be introduced into co-incineration, depending on the specificity of each installation and the clinker production process. In order to characterize the waste composition, analytical investigations are necessary. One of the parameters required of our customers is the sulfur content in waste. To meet these requirements, an ion chromatography method which was initially developed for the determination of sulfur content in fuels, was applied on other classes of samples as municipal waste and oil and sewage sludge. Three types of waste have been used for the experiments: RDF (resulting from municipal waste containing mainly plastics, textiles and paper), sewage sludge and oil sludge. The results obtained by ion-chromatography (sulfur content, standard deviation of repeatability and coefficient of variance) were compared with the values indicated of the relevant standards for determining the sulfur content of waste. Another comparison was made with the values obtained by the gravimetric method used in parallel.

\section{Materials and Methods}

\section{Sample collection}

The methods were tested on samples of: RDF (refuse-derived fuel) resulting from municipal waste containing mainly plastics, textiles and paper -4 different samples; sewage-sludge $(\mathrm{N})-4$ different samples; oil-sludge (OS) - 4 different samples. Until sample preparation, the samples are stored at 4 degrees maximum 7 days after their entry into the laboratory.

\section{Apparatus}

The analysis of sulfur as sulfate anion from wastes was carried out according to SR EN ISO 10304-1:2009 using a Dionex ICS-5000 + ion chromatography system (Thermo Scientific, Sunnyvale, CA, USA). The system is equipped with a conductivity detector, an IonPac ${ }^{\circledR}$ AS18 hydroxide selective anion-exchange column (2 $\mathrm{mm}$ ), operating at a flow rate of $0.25 \mathrm{~mL} / \mathrm{min}$, sample volume $5 \mu \mathrm{L}$ and incorporates an electrolytic eluent generator (for $30 \mathrm{mM} \mathrm{NaOH}$ production. All samples were prepared according to SR EN 15002:2015. Reduction of the particle size was performed by using a Rotor Beater Mill SR 300 Retsch for RDF samples and Vibratory Disc Mill RS 200 - Retsch for dried sewage sludge. Oil sludge sample was mixed using a Rotor Beater Mill SR 300. After the samples pre-treatment, the sulfur as sulfate anion was extracted by combustion in a calorimetric bomb Parr 6200 .

\section{Reagents and Calibration}

All reagents used were prepared with ultrapure water $(<0.1 \mu \mathrm{S} / \mathrm{cm})$ from a purification system (Ultra Clear TWF UV Siemens SG Water, Germany), and all chemicals used were of analytical quality. $30 \mathrm{mM}$ Sodium Hydroxide is the eluent solution for Ion chromatography method. Two $1000 \mathrm{mg} / \mathrm{L}$ certified solutions of sulfate (CertiPURMerck and $\underline{\text { Sulfate Standard for IC TraceCERT }}{ }^{\circledR}$, Sigma-Aldrich) were used for preparing and verifying the calibration curve. To assess the linearity, calibration curve was prepared in the range $1-100 \mathrm{mgSO}_{4}{ }^{2-} / \mathrm{L}$. The linear range of the curve was assessed by the value of correlation coefficient of the linear regression and the residuals. The intercept, slope, correlation coefficient and performance parameters obtained are given in Table 1 and Fig. 1. 
Table 1. Performance parameters of the method for sulfate anion determination by ion-chromatography method

\begin{tabular}{ll}
\hline \multicolumn{1}{c}{ Performance parameters } & \multicolumn{1}{c}{ Value } \\
\hline Measuring range & $1-100 \mathrm{mg} / \mathrm{L}$ \\
Linear regression equation & $\mathrm{Y}=0.4293 \mathrm{x}+0.1971$ \\
R correlation coefficient & 0.9998 \\
Detection limit, LOD & $0.07 \mathrm{mgSO}_{4} / \mathrm{L}$ \\
Quantitation limit, LOQ & $0.7 \mathrm{mgSO}_{4} / \mathrm{L}$ \\
Residual standard deviation, Sy & 0.2176 \\
Standard deviation, Sx0 & 0.507 \\
Coefficient of Variation, RSD & $0.92 \%$ \\
\hline
\end{tabular}

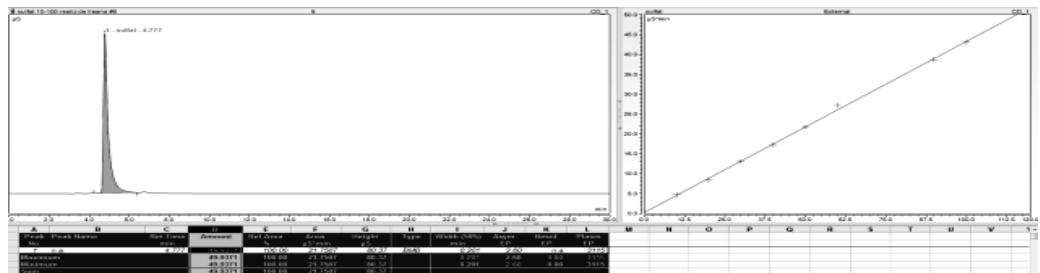

Figure 1. Calibration curve and retention time for sulfate anion determination

\section{Sample pre-treatment}

Drying, milling and sieving of the solid samples

European Standard 14582:2016 and SR EN 15002:2015 specifies the pre-treatment required for solid, pasty and liquid samples. As sulfur is an inorganic analyte, sample preparation was performed by the procedure recommended for inorganic chemicals. The samples were dried in air or in oven at $40^{\circ} \mathrm{C}$ until constant mass. Dry sewage sludge samples were milled and sieved to $200 \mu \mathrm{m}$, sealed in plastic containers and stored at $20^{\circ} \mathrm{C}$. In Fig. 2 are shown the samples of sewage sludge before and after pre-treatment.
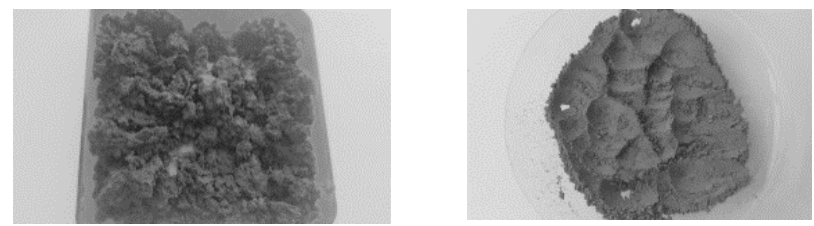

Figure 2. Sewage sludge sample before and after pretreatment

Dry samples of RDF were milled and sieved three consecutive times using a series of 3 sieves with the mesh size of 10, 2 and $0.5 \mathrm{~mm}$. In Fig. 3 are shown the samples of RDF after each stage of milling and sieving. 


\section{INTERNATIONAL SYMPOSIUM "THE ENVIRONMENT AND THE INDUSTRY", SIMI 2017, PROCEEDINGS BOOK}

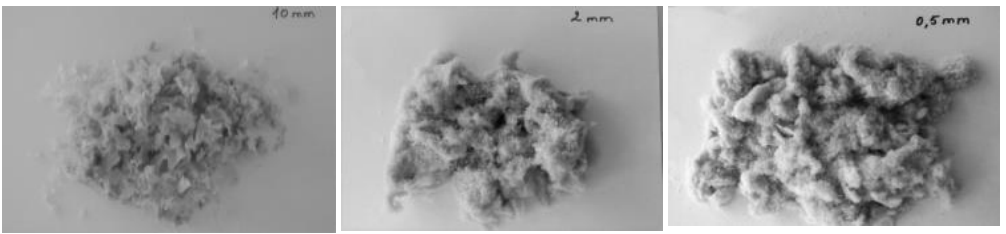

Figure 3. Samples of RDF after each stage of milling

Oil sludge contains volatile organic compounds so, this sample is not dried. In this case, the sample is mechanically mixed as recommended by the European Standard EN 15002:2015.

\section{Combustion of the samples in calorimetric bomb}

Sample combustion is commonly used to prepare solid matrices for analysis by IC. This involves total combustion of the sample in oxygen, which converts nonmetallic elements to volatile gaseous compounds. These gases can be collected into a suitable absorbing solution which can then be analyzed using IC (Jackson 2000). In our experiments, RDF, sewage sludge, and oil sludge samples were oxidized by combustion in a calorimetric bomb containing oxygen under pressure. Sulfur containing compounds were converted to sulfate anion which was absorbed in ultrapure water present in the bomb. The aqueous samples with sulfate content and the washing waters resulting from a rigorously rinsing of the bomb using ultrapure water were transferred and diluted in $250 \mathrm{ml}$ volumetric flask of. Aqueous solutions with anion sulfate content were analyzed in parallel by ion-chromatography and gravimetric methods, after a proper filtration through a $0.45 \mathrm{~mm}$ membrane based filter.

\section{Results and Discussion}

Results for sulfur content in samples of waste (RDF, sewage sludge and oil sludge) and standard deviation and relative standard deviation of the results are centralized in the Tables 2, 3 and 4. According to Fig. 4 one can observe the difference between the RSD results obtained by the ion-chromatography and the gravimetric method. The experimental data showed that the relative standard deviations for the determination of sulfur content in waste by ion-chromatography technique are situated in the range: $3.23 \%-6.25 \%$ and they are in accordance with the relevant standards. Also, the results are comparable and slightly more homogeneous than those obtained by the gravimetric method used as routine in our laboratory.

Table 2. Results obtained for sulfur content in samples of RDF

\begin{tabular}{|c|c|c|c|c|c|c|c|}
\hline \multicolumn{4}{|c|}{ Ion-chromatography } & \multicolumn{3}{|c|}{ Gravimetry } & \multirow{2}{*}{$\begin{array}{c}\text { Standard } \\
\text { requirements }\end{array}$} \\
\hline \multirow{2}{*}{ Sample } & $\mathbf{x}_{\text {mean }}$ & $\mathbf{S}_{\mathbf{r}}$ & RSD & $\mathbf{x}_{\text {mean }}$ & $\mathbf{S}_{\mathbf{r}}$ & RSD & \\
\hline & \multicolumn{6}{|c|}{ [\%] } & SR EN 15408:2011 \\
\hline RDF1 & 0.17 & 0.01 & 5.88 & 0.15 & 0.02 & 13.33 & $\begin{array}{c}{\left[\mathrm{SO}_{4}\right]=0.13 \%} \\
\mathrm{~S}_{\mathrm{r}}=0.02 \%\end{array}$ \\
\hline RDF2 & 0.16 & 0.01 & 6.25 & 0.14 & 0.02 & 14.28 & $\mathrm{RSD}=15.38 \%$ \\
\hline
\end{tabular}


Table 3. Results obtained for sulfur content in samples of oil sludge

\begin{tabular}{|c|c|c|c|c|c|c|c|}
\hline \multicolumn{4}{|c|}{ Ion-chromatography } & \multicolumn{3}{|c|}{ Gravimetry } & \multirow{3}{*}{$\begin{array}{l}\text { Standard } \\
\text { requirements }\end{array}$} \\
\hline \multirow{2}{*}{ Sample } & $\mathbf{X}_{\text {mean }}$ & $\mathbf{S}_{\mathbf{r}}$ & RSD & $\mathbf{x}_{\text {mean }}$ & $\mathbf{S}_{\mathbf{r}}$ & RSD & \\
\hline & \multicolumn{6}{|c|}{ [\%] } & \\
\hline OS.1 & 0.73 & 0.03 & 4.11 & 0.71 & 0.04 & 5.63 & $\begin{array}{c}\text { SR EN 14582:2017 } \\
{\left[\mathrm{SO}_{4}\right]=0.65 \%}\end{array}$ \\
\hline OS.2 & 0.84 & 0.04 & 4.76 & 0.84 & 0.05 & 5.95 & $\begin{array}{c}\mathrm{S}_{\mathrm{r}}=0.14 \% \\
\mathrm{RSD}=21.3 \%\end{array}$ \\
\hline OS.3 & 0.93 & 0.03 & 3.23 & 0.92 & 0.05 & 5.43 & $\begin{array}{c}\text { ASTM D129-13 } \\
{\left[\mathrm{SO}_{4}\right]=0.5-1 \%}\end{array}$ \\
\hline OS.4 & 0.41 & 0.02 & 4.87 & 0.39 & 0.03 & 7.69 & $\begin{array}{c}\mathrm{S}_{\mathrm{r}}=0.06 \% \\
\mathrm{RSD}=6.45-14.63 \%\end{array}$ \\
\hline
\end{tabular}

Table 4. Results obtained for sulfur content in samples of sewage sludge

\begin{tabular}{|c|c|c|c|c|c|c|c|}
\hline \multicolumn{4}{|c|}{ Ion-chromatography } & \multicolumn{3}{|c|}{ Gravimetry } & \multirow{2}{*}{$\begin{array}{c}\text { Standard } \\
\text { requirements }\end{array}$} \\
\hline Sample & $\mathbf{x}_{\text {mean }}$ & $S_{\mathbf{r}}$ & RSD & $\mathbf{x}_{\text {mean }}$ & $\mathbf{S}_{\mathbf{r}}$ & RSD & \\
\hline N1 & 0.98 & 0.05 & 5.10 & 0.98 & 0.07 & 7.14 & \multirow{5}{*}{$\begin{array}{c}\text { SR EN } \\
\text { 15408:2011 } \\
{\left[\mathrm{SO}_{4}\right]=1.06 \%} \\
\mathrm{~S}_{\mathrm{r}}=0.06 \% \\
\mathrm{RSD}=5.66 \%\end{array}$} \\
\hline $\mathbf{N 2}$ & 0.76 & 0.04 & 5.26 & 0.74 & 0.05 & 6.76 & \\
\hline $\mathbf{N 3}$ & 0.68 & 0.03 & 4.41 & 0.64 & 0.04 & 6.25 & \\
\hline N4 & 0.62 & 0.03 & 4.83 & 0.58 & 0.04 & 6.89 & \\
\hline N5 & 0.19 & 0.01 & 5.26 & 0.18 & 0.014 & 7.77 & \\
\hline
\end{tabular}

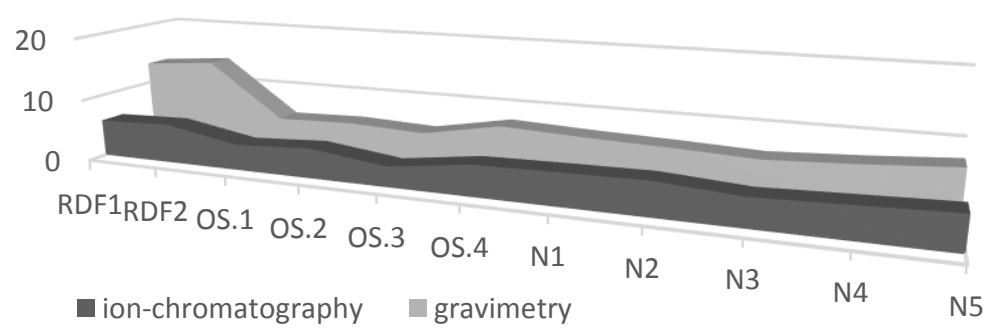

Figure 4. RSD values obtained for ion-chromatography and gravimetric methods

\section{Conclusions}

In this paper, an ion - chromatography method was applied for sulfur content determination in waste. Experiments were carried out with samples of RDF (refused derived fuel resulting from municipal waste containing mainly plastics, textiles and paper), sewage sludge and oil sludge. Due to the homogeneity of the results obtained and the analysis time which is much lower than in the case of the gravimetric determinations, ion-chromatography method is appropriate to be used for sulfur determination in studied waste.

\section{Acknowledgements}

This work has been supported by the Romanian Government through the project PN 1625041 13 , contract no. $38 \mathrm{~N} / 2016$. 


\section{References}

Arama, GM, Kim, L 2016, 'Using waste hierarchy concept for optimizing the management of the waste disposal amount and implicitly of the possible ecological risk', International Symposium "The Environment and The Industry”, National Research and Development Institute for Industrial Ecology ECOIND, Bucharest, pp. 66-72.

ASTM D129-13, `Standard Test Method for Sulfur in Petroleum Products (General High-Pressure Decomposition Device Method) '.

Jackson, PE 2000, 'Ion Chromatography in Environmental Analysis`, Encyclopedia of Analytical Chemistry, Ó John Wiley \& Sons Ltd, Chichester, pp. 2779-2801.

Puiu, D, Cruceru, LV 2016, 'Guidance tool for waste analysis in an accredited laboratory', International Symposium "The Environment and the Industry", National Research and Development Institute for Industrial Ecology ECOIND, Bucharest, pp. 81-88.

SR EN 15408:2011, 'Solid recovered fuels. Methods for the determination of sulphur $(\mathrm{S})$, chlorine $(\mathrm{Cl})$, fluorine $(\mathrm{F})$ and bromine $(\mathrm{Br})$ content'.

SR EN 14582:2017, 'Characterization of waste - Halogen and sulfur content Oxygen combustion in closed systems and determination methods`.

SR EN ISO 10304-1:2009, 'Water quality. Determination of dissolved anions by liquid chromatography of ions. Determination of bromide, chloride, fluoride, nitrate, nitrite, phosphate and sulfate'. 